\title{
Problem Research and Application of College Students' start-up under the Background of Internet + Age
}

\author{
Qin Weifu ${ }^{1, a}$ \\ ${ }^{1}$ Office of admissions and employment \\ Guangxi Vocational and Technical College, Nanning 530226,China \\ aqinweifugx@126.com
}

Keywords: College students, start up a business, Internet + age

\begin{abstract}
Internet age profoundly affects the social economy and it has provided a broad platform for college students' innovative entrepreneurial training. College students' start-up under the background of Internet + age, college students use the Internet to provide value-added services to make profits. This paper discusses concept and the connotation analysis of Internet + , explores the bottlenecks and difficulties of college students' innovative start-up under the background of Internet + , puts forward promotion strategies of college students' innovative undertaking. With the rapid development of computer network information technology and the popularity within the scope of the whole society, college students increasingly have closer contact with network information. The network as a kind of extremely important form of media has an important influence on college students' life, especially the advent of the era of Internet + in the new period has brought huge challenges for the college students' employment, also contributed to China's education personnel training work. Therefore, under the background of "+" Internet age, taking certain measures of education to cultivate college students' career ability has become a topic attracting the social attention from all walks of life.
\end{abstract}

\section{The introduction of Internet + age}

On March 5, 2015, in the third meeting of the $12^{\text {th }}$ National People's Congress conference, premier Keqiang Li stressed " to make Internet + action plan, to promote the mobile Internet, cloud computing, big data, the Internet of things and other industries combined with modern manufacturing industries, and to promote healthy development of e-commerce, industrial development of the Internet and Internet financial, to guide the Internet companies to expand the international market". Internet + action plan makes "Internet +" become a hot spot of social concern and focus. To understand the connotation of the "Internet +", the first is to know "the Internet. The Internet, also known as the Internet or the transliteration of the Internet, is the network and the network between the strings into a vast network of the general agreement that is linked together, form huge international network logic. Computer network interconnection between together method can be referred to as" networking ", on the basis of "networking" developed covering global interconnection network structure called the "Internet" around the world, known as "network connected with each other". From the aspects of technology is "composed of multiple interconnected computer networks, no matter adopt what kind of deal with the technology of network". The Internet mode is typically through an open concept and convenient way, sharing mode, provides a wide range of quality services, in the form of free form good user viscosity, to form the user scale and paid by advertising or other value-added services, a profit. In essence, the Internet mode is a new business model, it mainly takes the user as the center, give full consideration to the user demand, with "customer first, experience is king" as the principle, from product to product marketing around the user. Say that the Internet has to some extent changed people's way of life, and lead the user to adapt to this way.

The meaning of Internet + is to make full use of the Internet in the allocation of production factors and optimization and integration, innovation on the Internet with the depth of the economic society in various fields, to produce chemical reaction, the amplification effect, vigorously promote the real economy, innovation and productivity to form a wider range of Internet based facilities and 
implementation tools new form of economic development. The popular" Internet + "is" Internet + the traditional industries ", it is absolutely not a simple combination, but to use the Internet platform and information and communication technology, etc., make traditional industry and the Internet organic fusion depth, great play in the Internet market in the allocation of resources integration and optimization, to create a new pattern of development. For example, the internet + traditional markets produces Taobao, internet + traditional supper market produces Jingdong mall, the internet + traditional Banks produces Alipay, Internet + traditional matchmaker company produces Jiayuan and so on. From this perspective, we know that the thought of Internet + is being fully applied to the third industry comprehensively, and is to permeate the first and second industry actively. "Internet $+"$ thinking of advancing traditional industrial production mode and promote the transformation of agricultural production areas and bring new opportunities for them, provides an unprecedented broad space for development. "Internet +", although the increase with the increase of the contemporary college students in innovative entrepreneurial opportunities and improve the ways and methods of innovative undertaking and but college students' innovative undertaking bottlenecks and difficulties.

\section{The characteristics of Internet +}

The Internet has a huge customer base, it has up to 6.32 billion customers only in motherland, and the huge population means the huge market potential. The domestic uses the Internet to countless successful entrepreneurial enterprises through summarizing, we found that the success of Internet start-ups have some common features.

1. Less initial investment, the risk is relatively small. The Internet startup relies mainly on the developed network communication. For Internet entrepreneurs, if not a lot of projects, the funds required to initially not many, perhaps a computer + network + a cottage, a person "can begin. This is minus the traditional entrepreneurs to the rent, equipment, communication cost, labor costs and other expenses, so its initial investment and cost is low. Other web startups are characteristics of China resources, to a certain extent scattered or pass on the risks.

2. Focus on the user experience, mining the customer demand. Internet companies sell goods not only the product itself, more important is the participation of customers and meet the demand. Design and manufacture products according to customer requirements, and even exceed customer demand, customers become not only consumer goods, and to participate in product design and communication. Millet's success is well-established in this respect. It encourages users to further on research and development. Setting MIUI for example, the MIUI mobile phone operating system, millet mobile phone use 500000 enthusiasts to participate in the development of improved, and a third of the creative improvement from bedizens. Users on the system of any opinion can direct feedback in the BBS.

3. Use of social media marketing, gain customer loyalty. Social media marketing is the use of social media network, product display, reputation building, public relations management and customer maintenance such as a way of marketing. In particular is to use the website, online communities, Weibo, WeChat and App Internet tools such as to display their products and brands. The characteristics of individual communication, it is different from the traditional media has such characters as the bidirectional interaction, open communication, greatly reduce the distance between producers and consumers, also let consumers involved in the brand communication through this kind of good interaction, can increase the credibility of enterprises and the public to enterprise's trust, irrationality of consumers to the brand loyalty, form "fans economy".

4. The implementation of resource integration, concentration effect. Compared with traditional economy, Internet companies are using the Internet to collect, gather resources quickly, by the benefit sharing mechanism resources of main body participation enthusiasm, to create greater value. Tmall, Jingdong, the No 1 shop and other online integrated entity stores; where nets, Ctrip, way cows integrate tourism, hotel, ticketing and other resources; click a taxi, quick take a taxi cab and resource integration. Their common features are to create communication channels for merchants and user, and create a new channel for sales, and integration is one of the most important basis to 
the survival of the Internet companies.

\section{The problems of college students' start-up in the age of Internet+}

To raise student's innovation ability is the need of promoting the construction of an innovative country, is an important approach to alleviate the pressure of the college students' employment, is also the needs of the development of college students. "Internet + " background of contemporary college students innovative entrepreneurial opportunities challenges, there are many bottlenecks and difficulties. Difficulties mainly embodied in the following aspects:

First is lack of venture capital, without enough venture capital. Under the background of "Internet +", what the college students lack the most is venture capital, lack the access to innovative start-up capital platform and opportunity. The main source of college students' entrepreneurial venture capital is raising money with less help from school and society. Even if some sources of funds for small loans, philanthropy and government investment and the school a small amount of funding, the formalities for examination and approval of the funds, amount is small, high threshold, difficult access to capital. Under the background of the Internet industry innovative entrepreneurial activity itself is burning money, companies may also be losing money for a long time, the money is not enough innovation startup capital, college students alone self-raised funds and a small amount of funding is difficult to maintain for a long time, it determines the innovation of college students entrepreneurship natural disadvantages. On the other hand the risk investment fund for quality big project to investment, for the vast majority of college students' innovative entrepreneurial project more and more cautious.

The second is poor entrepreneurship environment. At present, the country lacks a good creative environment, although state and government have changed in recent years, but from the GEM (global entrepreneurship monitor) to see China belongs to the middle and lower levels. China's entrepreneurial environment is the complete lack of policies and regulations to protect, especially intellectual property rights protection, policy support, enterprise examination and approval in a lot of shortcomings. Such as tax, business and enterprise system, financing system and personnel allocation, etc are not to give policy support to the college students' innovative entrepreneurial activity. Under the background of "Internet +", very few mature business model, new business models are not the development and application. The traditional model of Internet enterprises most using virtual currency, payment management, business cooperation and the way of ads, and so on profit, and in domestic consumers used to free service, experience first, large and well-known enterprises are faced with a lack of successful business model, and the new college students' innovative undertaking enterprise.

The third is technical difficulty without the core technology. For college students' innovative undertaking, select "Internet + " industry must have corresponding technical advantage and service consciousness, difficulty is very big for the startup of the college students. Make full use of the school team advantage, perfect the knowledge structure of college students' innovative undertaking, for the school of business management form complementary advantages, talent and technology talents to create a unique technology or service to meet the market demand, keen to capture the market changes, develop customer experience very good technology and service, timely find higher core products and services. Even if the college students' innovative undertaking has overcome technology and products and services, but early due to lack of experience and innovative undertaking the core technical barriers is not high, strong extrusion by other enterprises, it is easy to imitate and surpass other enterprises.

\section{Strategies for students to improve their innovation start-up ability in the age of Internet +}

4.1 To increase investment, perfect the various facilities. At present, China attaches great importance on college students' innovative start-up, and also introduces practical encouragement policies. The society and schools should increase capital investment, financing and development, improve the base construction and incubation bases and relevant supporting policies and facilities. 
The school must complete the top design, the establishment of innovative entrepreneurial leadership team, actively explore new cooperation, to the cooperation between colleges and the manufacture-learning-research cooperation, and increase the intensity of innovative undertaking teacher training, efforts to improve innovation entrepreneurship curriculum construction, speed up the promotion innovation entrepreneurship education. The government should enforce policy support, give tax breaks for college students, simplify loan procedures, increase support means such as preferential policies. Schools and enterprises should give students' innovative entrepreneurial base and incubation bases and breaks the rent, financing guarantee, guiding the preferential policies such as the service. Business school students "elastic student status" system, ensure that students start-up time, solve the students' innovative entrepreneurial activity.

4.2 To build platforms, fully expand the business space. The society and schools should provide practice platform for college students' innovative undertaking, make full use of entrepreneurship lab, SYB courses and other hardware platforms, give full play to the "challenge cup" extracurricular academic science and technology work competition, such as college students' innovative entrepreneurial training programs, employment entrepreneurial BBS and etc. As the basic content of new college students' innovative undertaking education system, and actively cultivate the students' innovative entrepreneurial drive. Make full use of the "Internet +" competition, service outsourcing innovation entrepreneurship and the "three a" game, such as utilization of professional practice, graduation design and field work to provide internship opportunities to entrepreneurship, lets the student understand the Internet + enterprise operation process, experience the Internet business risks, etc. To invite outstanding business report successful alumni, experts and entrepreneurs, to share with their school junior drove to share their technology source of start-up stage, product positioning and services, to lay a good foundation for the college students' innovative undertaking.

4.3 The attack technology to ensure fair competition environment. Use the Internet for business, a potential crisis, is determined by the nature of the Internet. As a result of the domestic Internet market start time is short, the government of various regulatory incomplete, imperfect policies and regulations, the unfair competition environment. Internet merchant self supervision cost is high, the ability is weak, it will make some unscrupulous give him big drill its empty, will be given the wrong version of dishonesty, without the impact of the credit crisis. Therefore, college students venture to conquer the core technology and services, you can choose to learn the computer, students majoring in economics and management and legal team to match business, so both the technical support team as the source, management and law, and have to understand can lay the foundation for innovative entrepreneurial success. The government to ensure that the Internet market fair environment, strengthen supervision function, perfect laws and regulations, regulate the Internet business fair. Students entrepreneurial strengthening its supervision function, enhance the technological advantage, barriers to protect the core technology, is the college students' innovative undertaking lasting development sustainable.

4.4 Make up the experience, comprehensive integration of resources effectively. College students a startup, a serious shortage of entrepreneurial experience, take up less social resources, the school to cultivate the students to develop ways of thinking of the Internet era, guide students to reasonable use of resources, foster new type of all business groups. Schools cooperate with each other, cooperation between colleges and schools and the way of production-study-research cooperation, establish a multi-dimensional cooperation models, invited well-known entrepreneurs, well-known alumni and various professional students and communication channels in college students' school entrepreneurship and job and internship opportunities, technical support, share the solutions to problems exist in the entrepreneurial process, build up the students, teachers and entrepreneur collaboration platform of interactive communication, trying to get through the merchants and user communication channels, innovative marketing strategies, integrate all resources, for college students venture to provide the lack of experience. 


\section{Summary}

With the coming of information era, people gradually rely on the convenience of living service, real-time information update at anytime and anywhere that the Internet brings to them. College students start their business relying on Internet has the absolute development advantages such as knowledge literacy and also have relatively long term prospects for development, is also the driven strategy to perfect the innovation of our country, the important measure to implement the policy to encourage youth entrepreneurship, but also is also the effective way to achieve more employment opportunities with job creation and encourage entrepreneurship. The government, university and the society cooperate with each other and spread the concept of college students' Internet startup. College students' innovative undertaking has risen to the height of national strategy, their business problems must be settled with the power and support for college students to improve the success rate of entrepreneurship. Internet + traditional enterprise business are developing now which can not live without the support of national policy, colleges and universities, students' efforts so as to build a strong business atmosphere in the industry and cultivate more Internet elite.

\section{Acknowledgements}

2016 junior middle school teachers' basic ability improvement project.

\section{References}

[1] X. M. Zhang, X. Q. Liu. Construction of innovative entrepreneurial platform, training students' innovative undertaking ability [J]. Journal of experimental science and technology, 2010, 8 (6) : 117-118.

[2] K. Li, Y. S. Yang. Path exploration of college students' entrepreneurship education under the background of informatization [J]. Journal of Guangdong vocational and technical college, 2012, 19 (3) : $259 \sim 261$.

[3]L. C. Hua, B. Ding. College students' start-up ability education under the background of informatization [J]. Journal of Changchun college of education, 2015, (8) : 77-78.

[4]M. F. Bian. Analysis and research of cultivating the ability of college students' innovative undertaking under the background of Internet[J]. Science review, 2015, (19).

[5]Q. Duan. The innovation path to cultivate college students' career ability under the network era [J]. Journal of enterprise culture, 2015, (7). 